\title{
PHYSIOLOGICAL INTRAVASCULAR HEMOLYSIS OF EXERCISE. HEMOGLOBINEMIA AND HEMOGLOBINURIA FOLLOWING CROSS-COUNTRY RUNS
}

\author{
By D. ROURKE GILligan, M. D. ALTSCHULE, and E. M. KATERSKY \\ (From the Medical Service and the Medical Research Laboratories, Beth Israel Hospital, \\ and the Department of Medicine, Harvard Medical School, Boston)
}

(Received for publication May 19, 1943)

Studies on 3 cases of march hemoglobinuria were recently reported from this laboratory and the existing literature concerning this syndrome was reviewed (1). In 1 patient of our series and in some other reported instances, frank hemoglobinuria has been observed following walks of only 20 minutes' duration. Such occurrences are obviously unusual and are considered to be due to some as yet unrecognized and apparently benign abnormality (1). There are, however, other reported cases in which hemoglobinuria occurred only after very long, strenuous walks or after long runs. The question arises whether intravascular hemolysis, giving rise to hemoglobinemia and sometimes hemoglobinuria, occurs with sufficient frequency in certain types of strenuous exercise of long duration to be considered physiological. To gain information in this regard, a study was made of the incidence and degree of intravascular hemolysis in normal individuals performing long strenuous runs; the results of these studies and of other urinary and blood studies pertinent to the problem are reported and discussed herein.

\section{MATERIAL AND METHODS}

Material. Studies were made in groups of young subjects performing runs as follows: (1) 11 men, aged 17 to 18 years, after a cross-country run of 2.6 to 2.8 miles, in 14 to 18 minutes; (2) 11 men, aged 19 to 21 years, after a cross-country run of 4.5 to 5.1 miles, in 23 to $31 \mathrm{~min}$ utes; and (3) 26 men, aged 18 to 65 years, after a marathon run of 10 to 26.2 miles. In addition, comparative studies were made in 1 subject after the 26.2 mile marathon run, after a 5-hour period of exercise on the bicycle ergometer, after a 26.2 mile walk with a 52-pound pack on his back, and after an additional run of 11.2 miles in 76 minutes and 19 seconds.

Methods of study. A blood sample was taken from an antecubital vein, without stasis, within 15 minutes after completion of exercise. The blood for plasma hemoglobin measurement was drawn as suggested by Ham (2) : a sterilized syringe and needle, previously rinsed with sterile saline solution, were used; $5.0 \mathrm{cc}$. of blood were introduced into a tube containing $0.5 \mathrm{cc}$. of 3.0 per cent sodium citrate solution. The tube was stoppered and gently inverted several times to secure mixing. The plasma specimen was removed from the citrated blood samples from one-half to one and one-half hours after the blood was drawn. In many instances, $5.0 \mathrm{cc}$. of additional blood were placed over oxalate mixture for studies of hematocrit and of erythrocyte fragility. A sample of urine was collected shortly after blood was taken. Examination of the abdomen for the presence of hepatic or splenic enlargement was made at the end of exercise.

Chemical methods. The chemical methods utilized were described in detail in a previous publication (3). The concentration of hemoglobin in the plasma and urine was measured by the benzidine method as described by Bing and Baker $(4,5)$, with slight modification (3). Tests showed that no appreciable change in the plasma hemoglobin value occurred when the citrated blood sample remained at room temperature for 2 hours before separating the plasma; these tests were made in order to make certain that the necessary standing of the blood for from 30 to 90 minutes, between the time it was drawn at the place of termination of the exercise and the removal of the plasma in the laboratory, resulted in no measurable hemolysis. It was also demonstrated that the amount of hemoglobin in the plasma was not affected by transporting the blood from the field to the laboratory. The plasma hemoglobin values of some 50 normal subjects, who had not undertaken any strenuous exercise on the day of study, revealed values usually of 1.0 to $6.0 \mathrm{mgm}$. per 100 cc., with a rare value between 6.0 and $9.0 \mathrm{mgm}$. per 100 cc. and an average value of $4.0 \mathrm{mgm}$. per cent. We believe that this variability between 1.0 and $6.0 \mathrm{mgm}$. of hemoglobin per $100 \mathrm{cc}$. of plasma is not a true variability in the plasma concentration of the circulating blood, but is more likely occasioned by slight in vitro changes. This impression is gained from the fact that 2 blood samples, drawn within a period of a few minutes from a given subject at rest, not infrequently vary by 2.0 to $4.0 \mathrm{mgm}$. per $100 \mathrm{cc}$. Although it is perhaps true that minimal extravascular hemolysis cannot be avoided, no plasma hemoglobin value after exercise has been considered increased unless it was higher than the uppermost limit encountered in normal resting individuals, namely, 9.0 mgm. per 100 cc.

The bilirubin concentration of the plasma was measured by the method of Malloy and Evelyn (6). The to- 


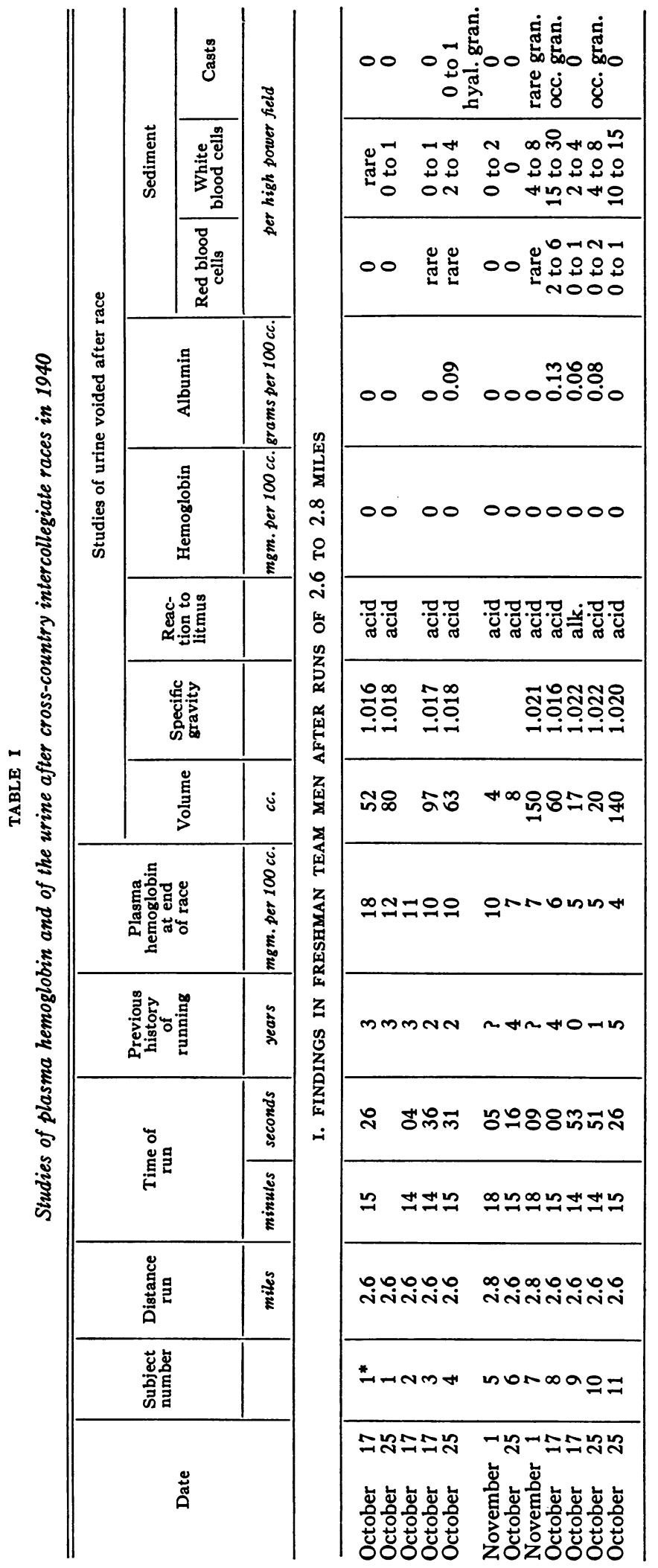

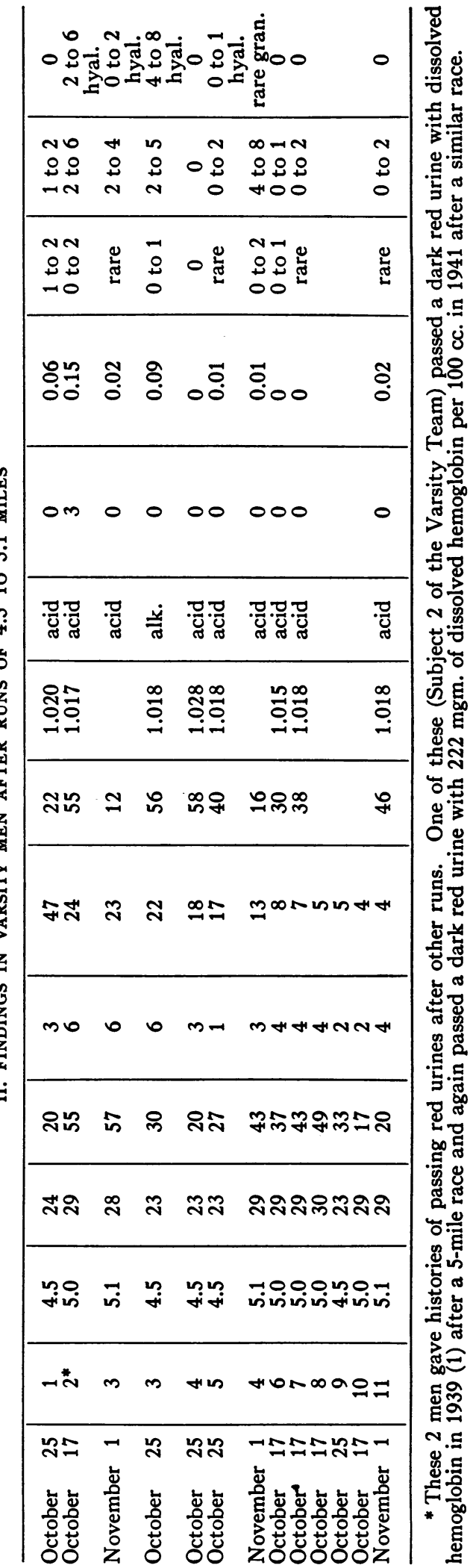


tal protein concentration of the urine was measured gravimetrically after precipitation with trichloroacetic acid (3). When the total protein was less than approximately $30 \mathrm{mgm}$. per $100 \mathrm{cc}$., the concentration was estimated by comparison of the turbidity of the urine with that of standards after the addition of 5.0 per cent solution of sulfosalicylic acid. Spectrophotometric examination of plasma and urine specimens were made for us by Dr. O. H. Lowry of the Department of Biochemistry of the Harvard Medical School; a König-Martens type of spectrophotometer was used. The fragility of the red blood cells in hypotonic saline was measured quantitatively, essentially as described by Hunter (7), with the following modifications: oxalate mixture was used as an anticoagulant, the blood was oxygenated for 3 minutes in air, and after transferring the samples of blood to the saline solutions, the mixtures were allowed to stand for 1 hour. In most instances, a phosphate buffer solution, giving a $\mathrm{pH}$ of 7.4 , was added to the saline solution, according to the suggestion of Dr. A. Baird Hastings of the Department of Biochemistry of the Harvard Medical School; the final salt concentrations were calculated in osmolar concentration and expressed in equivalent per cent of pure sodium chloride solutions.

\section{RESULTS}

\section{Plasma and urinary hemoglobin findings}

Cross-country runs. Of 11 Harvard freshmen who ran 2.6 to 2.8 miles in 14 to 18 minutes, 5 had plasma hemoglobins of 10.0 to $18.0 \mathrm{mgm}$. per $100 \mathrm{cc}$. (i.e., above the upper limit of normal, 9.0 mgm. per $100 \mathrm{cc}$.) at the end of the race (Table I). One of these 5 ran again and had an increased plasma hemoglobin on the second run also (Table I). Urines collected in 10 of these subjects, following the run, were of normal color and showed negative benzidine reactions.

Of 11 Harvard varsity track men who ran 4.5 to 5.1 miles in 23 to 31 minutes, 5 had definitely reddish plasma with plasma hemoglobin values elevated to 17 to $47 \mathrm{mgm}$. per $100 \mathrm{cc}$. (Table I). Studies made after another run in 2 of these 5 subjects also showed increased plasma hemoglobin concentration. Urines were collected after the runs in 8 of the 11 subjects, including the subject who showed a plasma hemoglobin of $47 . \mathrm{mgm}$. per $100 \mathrm{cc}$; the urines were all of normal color but hemoglobinuria was detected in one specimen by the benzidine test.

Two of these subjects who showed hemoglobinemia, following these cross-country runs, also gave histories of having passed red urines on other occasions following runs. One of these subjects passed a red urine after a race in 1939, i.e., a year before these statistical studies were made, and again in 1941, a year after these studies. In both instances, the urine became normal in color and showed no hemoglobin or albumin on the morning following the race. There were no symptoms at the time of the hemoglobinuria.

Marathon runs. The plasma hemoglobin values after the marathon run were elevated above the upper limit of normal in 18 of the 22 marathon runners who ran the entire 26.2 miles (Table II). The plasma hemoglobin values of these $18 \mathrm{sub}$ jects varied from 10 to $44 \mathrm{mgm}$. per $100 \mathrm{cc}$. and averaged $18 \mathrm{mgm}$. per $100 \mathrm{cc}$. In 11 of these 18 cases (Cases 1 to 11 , inclusive), the plasma hemoglobin was greater than $15 \mathrm{mgm}$. per $100 \mathrm{cc}$. In these instances, there was a definite reddish discoloration of the plasma. Four of these subjects showed hemoglobinuria, with concentrations from a trace to as high as 0.4 gram of dissolved hemoglobin per $100 \mathrm{cc}$. of urine; 3 of these urines were discolored from light brownish to very dark burgundy red. The hemoglobinuria occurred in the 4 subjects who showed the higher plasma hemoglobin values at the end of the run (Table II). Two of the subjects who showed hemoglobinuria at the end of the race were studied for several hours after the race (Table III). Hemoglobinemia and hemoglobinuria disappeared in both cases within 3 and 4 hours after the end of the race.

Four of the marathon runners had histories of passing red urines on one or more previous occasions following long runs; 1 of these subjects (Case 6, Table II) showed hemoglobinuria after the race of the present study, and again, 11 months later after another long run (Table II).

There was no correlation between the age of the runners or the number of years or state of training and the occurrence of hemoglobinemia or hemoglobinuria, either in the subjects who ran the marathon (Table II) or in those who ran the shorter races (Table I).

\section{Further observations during various exercises on a marathon runner with hemoglobinuria}

Further studies on the production of intravascular hemolysis during walking, bicycling, and running a shorter distance were made in the case 


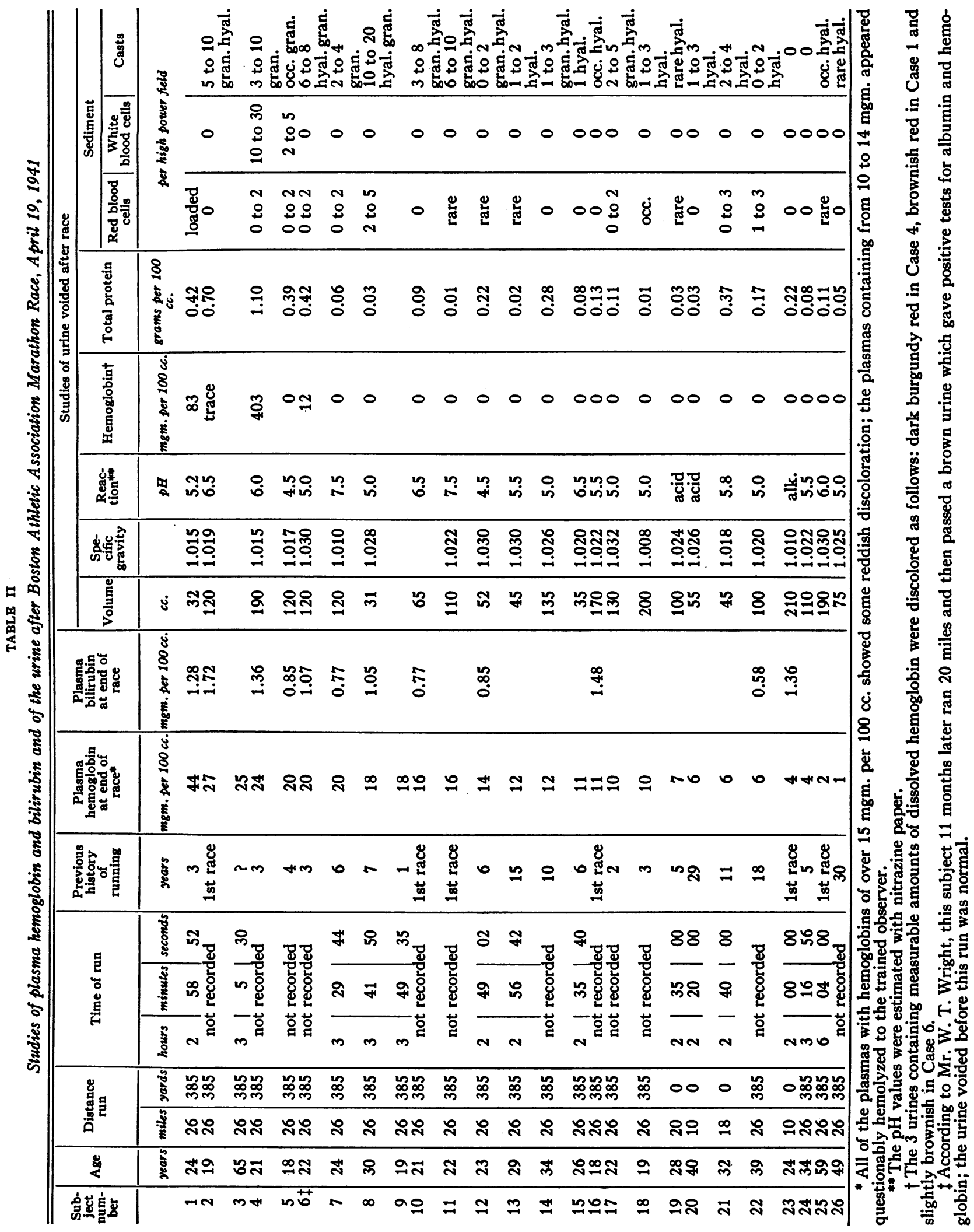


TABLE III

Further observations in 2 subjects showing hemoglobinuria at end of the marathon race

\begin{tabular}{|c|c|c|c|c|c|c|}
\hline \multirow[b]{2}{*}{ Subject number* } & \multirow[b]{2}{*}{ Time } & \multicolumn{2}{|c|}{ Plasma } & \multicolumn{3}{|c|}{ Urine } \\
\hline & & Hemoglobin & Bilirubin & Volume & Hemoglobin & Total protein \\
\hline 4 & $\begin{array}{l}\text { End of race } \\
2 \text { hours after } \\
3 \frac{1}{3} \text { hours after }\end{array}$ & $\begin{array}{c}\text { mgm. per } 100 c c . \\
24 \\
10 \\
6\end{array}$ & $\begin{array}{c}\text { mgm. per } 100 c c . \\
1.36 \\
1.29 \\
1.29\end{array}$ & $\begin{array}{l}c c . \\
190 \\
105 \\
115\end{array}$ & $\begin{array}{c}\text { mgm. per } 100 \mathrm{cc} . \\
403 \\
6 \\
\text { trace }\end{array}$ & $\begin{array}{c}\text { mgm. per } 100 \mathrm{cc} . \\
1100 \\
254 \\
22\end{array}$ \\
\hline 6 & $\begin{array}{l}\text { End of race } \\
3 \text { hours after } \\
4 \frac{1}{2} \text { hours after }\end{array}$ & $\begin{array}{r}20 \\
6 \\
6\end{array}$ & $\begin{array}{l}1.07 \\
1.18 \\
1.12\end{array}$ & $\begin{array}{r}120 \\
90 \\
75\end{array}$ & $\begin{array}{r}12 \\
0 \\
0\end{array}$ & $\begin{array}{c}416 \\
78 \\
0\end{array}$ \\
\hline
\end{tabular}

* The subject numbers are the same as in Table II.

showing the largest degree of hemoglobinuria following the marathon (Case 4, Table II). A run of $\mathbf{1 1 . 2}$ miles in 76 minutes resulted in a rise of plasma hemoglobin to $13 \mathrm{mgm}$. per cent from the control level of $2.0 \mathrm{mgm}$. per cent. Neither hemoglobinuria nor albuminuria occurred; a few leukocytes appeared in the urine. The plasma bilirubin rose from 0.46 to $0.60 \mathrm{mgm}$. per cent and remained at that level for another hour. The hematocrit was unnchanged. A walk of 26.2 miles with a 52-pound pack caused no change in plasma hemoglobin; the urine also showed no changes except for the appearance of a few cells. Plasma bilirubin, hematocrit, and erythrocyte fragility were the same before and after. Work on a stationary bicycle for 5 hours, against a resistance of $5.0 \mathrm{kgm}$., during which time the speedometer showed a change equivalent to 73 miles, likewise resulted in no increase in plasma hemoglobin. The urine showed no hemoglobinuria or albuminuria; a very few cells appeared in the urine. Plasma bilirubin and erythrocyte fragility were the same before and after the work. The hematocrit showed a questionable increase.

\section{Spectrophotometric studies}

Spectrophotometric examinations of the plasma of Cases 1, 4, and 6 in the marathon series, and of the urine in Cases 1 and 4, and examination of the plasma of 1 runner (Case 2, Table I) of the 5mile cross-country race revealed in each instance a point of maximum absorption of $576 \mathrm{~m} \mu$ which corresponds with the point of maximum absorption of the alpha band of human oxyhemoglobin. These findings show conclusively that the plasma and urinary pigments were hemoglobin and not myoglobin, since the point of maximum absorption of the alpha band of oxymyoglobin is $581 \mathrm{~m} \mu$. There were no methemalbumin bands observed in the plasma and the Schumm test was negative in 3 of the marathon runners with plasma hemoglobin values of 20 to $44 \mathrm{mgm}$. per cent (Table II, Cases 1,4 , and 6 ).

\section{Plasma bilirubin studies}

The plasma bilirubin concentration, measured in 12 of the marathon runners, 11 of whom ran the whole 26.2 miles, ranged from 0.58 to $1.72 \mathrm{mgm}$. per $100 \mathrm{cc}$., with 10 of the values $0.8 \mathrm{mgm}$. per 100 cc. or higher (Table II). These values are distinctly elevated; an average value found in 36 normal subjects, using the same method, was 0.32 mgm. per $100 \mathrm{cc}$. and the range was from 0.1 to $0.8 \mathrm{mgm}$. per $100 \mathrm{cc}$. There was no correlation between the degree of hemoglobinemia and the degree of bilirubinemia at the end of exercise. In 2 subjects, studied 4 hours after the end of the race, the bilirubin was still elevated to levels of 1.3 (Case 4) and 1.1 (Case 6) mgm. per $100 \mathrm{cc}$. (Table III). Subsequent bilirubin values found at rest in Case 4 were 0.3 and $0.4 \mathrm{mgm}$. per $100 \mathrm{cc}$. Enlargement of the liver or spleen was not detected in any of the runners.

\section{Erythrocyte fragility studies}

Quantitative studies of the fragility of the red blood cells in hypotonic saline solution were made in 6 of the subjects after the marathon run. Five of these subjects had hemoglobinemia and 1 of these 5 had hemoglobinuria (Case 1, Table II). In all instances, the fragility curves fell within the 


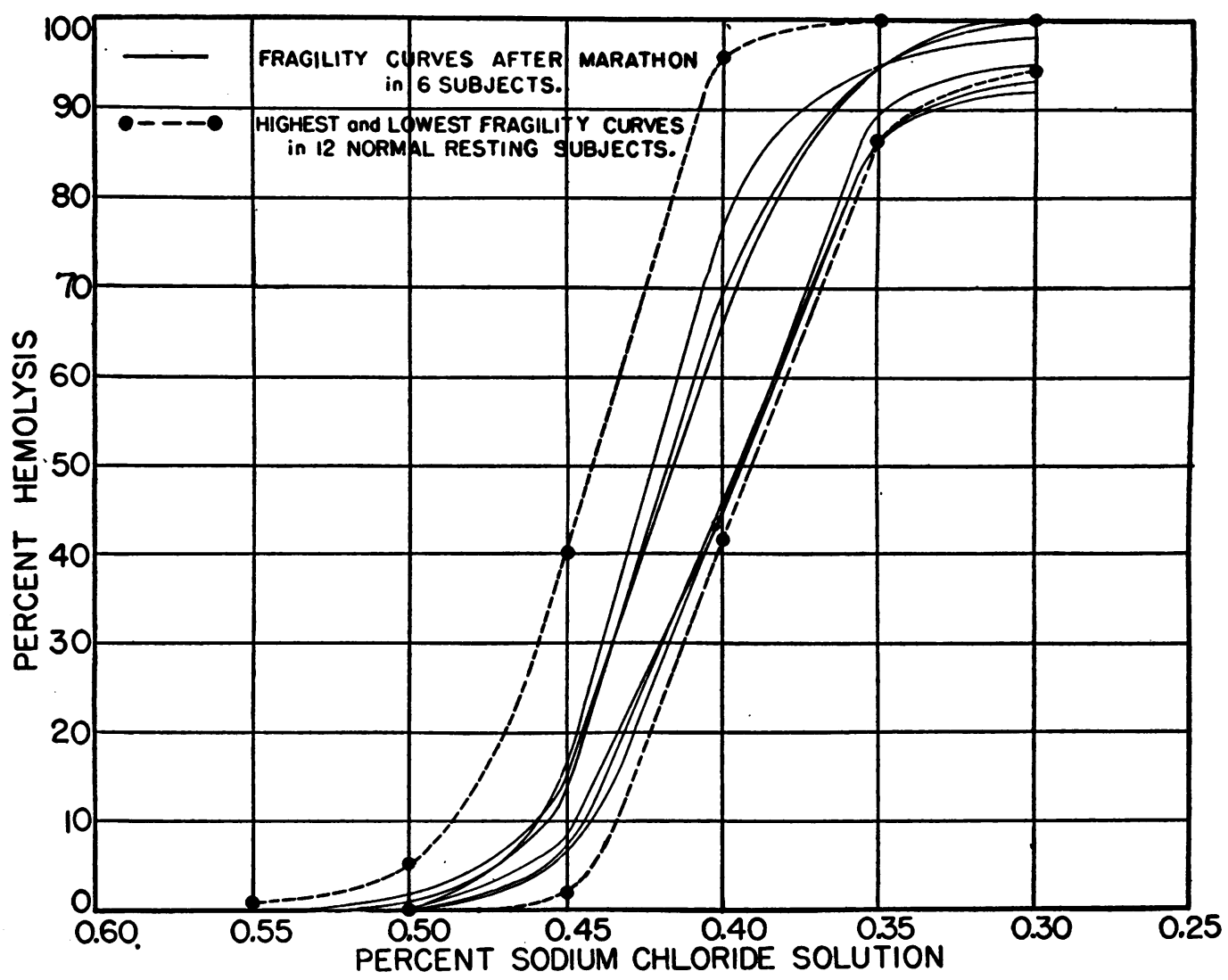

Fig. 1. Erythrocyte Fragility Curves After the Marathon Run and in Normal Resting SUBJECTS

range of those observed in normal subjects (Figure 1).

\section{DISCUSSION}

The present study is, to our knowledge, the first quantitative statistical study of hemoglobinuria and hemoglobinemia occurring in subjects following long strenuous runs.

There are now available in the literature reports of a total of some 13 cases in which hemoglobinuria occurred in young men during runs. Dickinson (8), in 1894, reported 1 case of hemoglobinuria which occurred after a 3-mile run and another case which occurred after a strenuous tennis match. This author (8) also stated that it was recognized in English sport circles that the urine was sometimes red after a strenuous run during the beginning of training. Three cases have been reported in which hemoglobinuria was noted after runs as short as 1 or 2 miles $(1,9)$.
Eight cases in which hemoglobinuria occurred after long cross-country or marathon runs have been reported $(1,10$ to 13$)$. In 1 of these cases (11), hemoglobinuria also developed after strenuous running for a long time in a game of "Fussball." It is of interest also that Hastings (14) has observed hemoglobinemia in untrained dogs after they ran for 20 miles on the treadmill.

The fact that only 13 cases of hemoglobinuria following runs have been reported in the literature affords no accurate information concerning the incidence of occurrence of intravascular hemolysis during this exercise. As was stressed recently (1), hemoglobinuria following exercise occurs only when the plasma hemoglobin is increased considerably; an amount of exercise just short of that required to produce hemoglobinuria in subjects with march hemoglobinuria does nevertheless result in a definite elevation of the plasma hemoglobin (1). Hemoglobinuria is therefore a secondary manifestation of intravascular hemolysis and 
occurs only in instances with the higher concentrations of plasma hemoglobin.

The single most pertinent published observation concerning the incidence of occurrence of hemoglobinuria during strenuous runs is that of Jundell and Fries (13) in 1911. During a statistical study of the albuminuria of exercise, these authors noted 4 cases of hemoglobinuria among 39 subjects who ran distances of 10,000 meters (6.2 miles) to 42,194 meters (26.2 miles). In these 4 cases the urine was described as bright red, brownred, or dark blood-red, and all gave strongly positive guaiac reactions; there were no red cells or very few in the urinary sediments. The urines in 2 of these cases were examined spectroscopically and showed oxyhemoglobin bands; in 1 instance, the plasma of a blood sample, drawn 1 hour after the run, was reddish brown and showed oxyhemoglobin bands on spectroscopic examination. Examinations of the urine for hemoglobin were not made following runs in any of the 39 competitors except those 4 cases in which the urines were obviously red, nor were plasma examinations made in any but the 1 case noted (13). It is important that the incidence of frank hemoglobinuria, i.e., reddish discoloration of the urine due to dissolved hemoglobin, after long-distance runs, in Jundell and Fries' series (13) and in our study (Table II) is quite similar. Jundell and Fries observed 4 cases of frank hemoglobinuria in a series of 39 subjects who ran from 6.2 to 26.2 miles, while 3 cases of frank hemoglobinuria and 1 case in which a trace of hemoglobin was detected by chemical analysis were found in our series of 26 subjects running from 10.0 to 26.2 miles. ${ }^{1}$

1 Mr. William T. Wright of the John Hancock Life Insurance Company recognized an additional instance in a marathon runner, during the course of a study on the urine of runners in the North Medford Road Race (20 miles) on March 14, 1942. A sample of urine was obtained from J. M. which gave positive tests for albumin and hemoglobin, although it contained no erythrocytes; his urine was normal immediately before the race and again 24 hours after it. Through the cooperation of $\mathrm{Mr}$. Wright, we were able to study J. M. after the B. A. A. Marathon of 1942 and obtained the following data: J. M. ran the 26 miles and 385 yards in 3 hours, 3 minutes, and 40 seconds. Thirty minutes later he voided $37 \mathrm{cc}$. of dark amber urine with a specific gravity of 1.032 and containing a large amount of albumin, a few leukocytes
If the urine alone had been studied after the race in the 11 freshmen running races of 2.6 to 2.8 miles in approximately 15 minutes (Table I), no evidence of any intravascular hemolysis would have been detected; however, the plasma hemoglobin studies revealed slight but definite intravascular hemolysis in 5 of the 11 men. Similarly, during the 4.5 to 5.1 mile runs, performed by the varsity team in approximately 23 to 31 minutes, hemoglobinuria occurred in only 1 of the 11 subjects, whereas a considerable amount of hemoglobinemia, at times sufficient to give a definite reddish tinge to the plasma and to be detectable with the Zeiss hand spectroscope, was present in 5 of the 11 subjects at the end of the race. The incidence of detectable hemoglobinuria after the 2.6 to 5.1 mile runs in college men, namely, 1 case in 22 subjects, would certainly be too low to demonstrate the benign physiological nature of the intravascular hemolysis of exercise; however, the incidence of hemoglobinemia, namely, 10 cases in 22 subjects, is sufficiently high to suggest that intravascular hemolysis during such exercises is quite normal.

A quantitative study of plasma hemoglobin revealed a strikingly high incidence of increased intravascular hemolysis in those subjects who ran 26.2 miles in the marathon race; 18 of the 22 men studied had suspiciously reddish to definitely reddish plasmas and quantitative hemoglobin measurements revealed plasma hemoglobin values distinctly above normal (Table II). Four of the subjects running in the marathon showed free hemoglobin in the urine; these 4 were the subjects with the highest plasma hemoglobin values, namely, $20 \mathrm{mgm}$. to $44 \mathrm{mgm}$. per $100 \mathrm{cc}$. at the end of the race (Table II).

Although hemoglobinuria in exercise occurs only in the cases with higher plasma hemoglobin values, the plasma level at which hemoglobinuria

and granular casts, and rare erythrocytes. This urine contained $15 \mathrm{mgm}$. of hemoglobin per $100 \mathrm{cc}$. An hour and one-half later his urine still contained a small amount of albumin but no hemoglobin. He was a 32-year-old white mechanic who had noted the occurrence of "black" urine $\mathbf{5}$ years ago, when he began to run distances over 5 miles. There were no associated symptoms of any sort; hemoglobinuria did not occur after exposure to cold. Physical examination was entirely normal; the blood Hinton and Kahn reactions were negative. 
occurs following exercise appears to be considerably lower than the level required to produce hemoglobinuria in normal man when hemoglobin is injected intravenously $(3,15)$. In the marathon runners, a somewhat higher level of plasma hemoglobin than that found at the end of the race may have obtained earlier in the run, for work is performed most rapidly earlier in the race, especially in those subjects who take some 4 or more hours to finish the course of 26.2 miles. Whereas hemoglobinuria was observed in 4 of 5 urines from subjects with plasma hemoglobin levels of 20 to $44 \mathrm{mgm}$. per cent at the end of the 26 mile marathon race, hemoglobinuria was detected in only 1 of the 4 urines from subjects with plasma hemoglobin levels of 22 to $47 \mathrm{mgm}$. per cent after the 5-mile cross-country race. The plasma hemoglobin values were probably at their highest point at the end of these shorter cross-country races.

There are not available sufficient statistical data to demonstrate to what extent exercises other than running lead to physiological intravascular hemolysis. However, there are reports indicating that very strenuous marching may lead to hemoglobinemia and hemoglobinuria in normal individuals. Albu and Caspari (16) reported the occurrence of reddish yellow and dark red urines, showing oxyhemoglobin bands by spectroscopic analysis, in 2 of 3 subjects after a most strenuous march of 202 kilometers (125 miles) in an endurance walking contest. Feigl (17) examined the plasma spectroscopically and the urine by the qualitative benzidine test for hemoglobin in 27 men after an army pack march of 35 kilometers ( 21.7 miles); he reported finding oxyhemoglobin in the serum of 6 and a positive benzidine test in the urine of 19 of the 27 cases after the march. Of the urines containing no erythrocytes which showed a positive benzidine test, some were voided in cases in which there was no oxyhemoglobin or hematin detected in the serum. Because of the qualitative nature of the study, these findings are difficult to interpret, especially since there is no mention of any reddish discoloration of the serum or urine in any of the cases. Further statistical studies of the incidence of intravascular hemolysis in normal individuals during marching would be of interest. In the present study, the marathon runner (Case 4 , Table II) with the most marked hemoglobinuria showed no evidence of intravascular hemolysis after a 26mile walk with a 52 -pound pack.

It has been questioned by several authors (18 to 20) whether the red pigment of the urine in march hemoglobinuria is not the muscle pigment myoglobin rather than hemoglobin. Our own studies in 3 previously reported cases of march hemoglobinuria (1), and a similar spectrophotometric observation by Witts (21) in his case, showed, however, that the plasma and urinary pigments in these cases were hemoglobin and not myoglobin. Similarly, in several of the cases of the present study, the red pigment of the plasma and urine was identified spectrophotometrically as hemoglobin and not myoglobin.

The mechanism of the intravascular hemolysis of exercise is obscure (1). Its occurrence has been recorded in man only following the exercise of walking or running, and in dogs, only after running. Equal or more strenuous exercise of other types in man does not cause it (1). There are reported in the literature 3 cases of hemoglobinuria following walks in the usual upright position, in which cases hemoglobinuria did not occur following similar or longer walks in a slightly kyphotic position (1, 22 to 24$)$. Most subjects with march hemoglobinuria show no lordosis of the lumbar spine (1), and in the present study, there appeared to be no correlation between body build or standing posture and the occurrence of intravascular hemolysis during runs.

Although these evidences of hemolysis, namely, the appearance of red plasma and less frequently red urine, occur after strenuous runs, the total amount of blood destroyed intravascularly is undoubtedly very small. It may be calculated that the hemoglobin from less than $10 \mathrm{cc}$. of normal blood is sufficient when released into the plasma to cause a hemoglobinemia of approximately 50 mgm. per $100 \mathrm{cc}$. of plasma in a subject with a blood volume of 5 liters and a normal hematocrit. The findings of a previous study (3), in which hemoglobin in solution was injected intravenously in normal subjects, accord with this statement. These injection studies also demonstrated that the plasma hemoglobin level does not become normal again for about 5 hours after the injection of sufficient hemoglobin to cause a plasma level of 50 mgm. per $100 \mathrm{cc}$. Since the plasma hemoglobin 
level was not greater than $50 \mathrm{mgm}$. per $100 \mathrm{cc}$. after the runs in any of the subjects of the present report, and since increased levels were not maintained long, it must be concluded that the hemoglobin of not more than approximately $10 \mathrm{cc}$. of blood was destroyed. This is approximately true even when there was some hemoglobinuria. The greatest urinary hemoglobin output occurred in Case 4 after the marathon; the first urinary specimen voided after the race contained a total of 0.77 gram hemoglobin and the following 2 specimens contained a total of less than 0.01 gram. The total hemoglobin excreted in the urine therefore would be contained in about $5.0 \mathrm{cc}$. of normal blood. These findings are in marked contrast to those in dogs in which anemia, reticulocytosis, and increased excretion of bilirubin may occur after long runs every day for several days (25 to 28). Whether there was blood destruction in our subjects other than that which occurred intravascularly cannot be answered by the data of this paper. Addition of erythrocytes to the circulating blood during prolonged exercise has been reported (29 to 31 ). The hematocrits following exercise in our subjects after the marathon were entirely normal; no control values were obtained before the run.

The increased concentrations of bilirubin in the plasma after the marathon race may have been due to decreased liver function consequent to hepatic ischemia during the exercise. The fact that the hyperbilirubinemia occurred in the absence as well as in the presence of hemoglobinemia demonstrates that it did not result from intravascular hemolysis; the degree and duration of hemoglobinemia were in no instance sufficient to give rise to such high levels of bilirubinemia (3). Although we have not been able to find reference in the literature to hyperbilirubinemia after exhausting exercise, there are reports of hyperbilirubinemia in man during anoxia at high altitudes (32) and of impaired bilirubin excretion in dogs during anoxia from low oxygen tensions (33).

It has been repeatedly demonstrated that normal individuals excrete albumin and formed elements in the urine after strenuous exercise $(13,34$ to 38). The incidence of occurrence of albuminuria, and the excretion of formed elements in the urine following the runs reported here, accord with the findings of Jundell and Fries (13). As observed in Tables I and II, the urinary findings after strenuous exercise may be quite the same as observed in nephritis; in subjects with normal kidneys, however, albuminuria disappears and the urinary sediment becomes normal in one to a few hours after the cessation of the exercise. In certain instances, the specific gravity of a urine collected following strenuous exercise may be sufficiently high to allow differentiation of this urine from the urine in chronic glomerular nephritis. Sometimes, however, the specific gravities following exercise may be within the range usually observed in advanced chronic glomerular nephritis. In 2 of the cases reported above (Table III) which were studied for some hours following the end of exercise, the urine became completely normal 3 hours after the termination of runs which produced albuminuria, hemoglobinuria, and the excretion of formed elements.

The frequent occurrence of these temporary renal changes manifested by albuminuria and the appearance of abnormal elements in the urinary sediment, and by decreased glomerular filtration (38) during repeated strenuous exercise over many years, has never been shown to result in any permanent kidney damage. Similarly, the repeated occurrence of the relatively mild hemoglobinemia and hemoglobinuria following exercise has never been known to result in damage to the kidneys. $^{2}$

The importance of differentiating the physiological intravascular hemolysis of exercise from pathological conditions leading to the passage of red urine is obvious. The benign nature of the albuminuria of exercise has been recognized for a long time. That the passage of a red urine following strenuous runs or walks may be equally as benign has not been generally recognized, however. The findings of this study are of particular importance at this time, when large numbers of young men in the armed forces are accomplishing extremely strenuous physical feats.

\section{SUMMARY AND CONCLUSIONS}

1. Studies of intravascular hemolysis, as measured by the appearance of hemoglobinemia and

\footnotetext{
2 As suggested previously (1), alkalinization of the urine during the period of hemoglobinuria provides a precautionary measure against precipitation of hemoglobin in the renal tubules.
} 
hemoglobinuria, have been made in groups of athletes following 2.6 to 26.2 -mile cross-country runs. The plasma bilirubin, the red cell fragility, the hematocrit, and the urinary albumin and sediment were also studied.

2. Hemoglobinemia was observed in 5 of 11 young athletes who ran 2.6 to 2.8 miles, in 5 of 11 athletes who ran 4.5 to 5.1 miles, and in 18 of 22 men who ran 26.2 miles.

3. Hemoglobinuria was observed in 1 of these athletes on 3 occasions after 5 -mile runs. Hemoglobinuria occurred in 4 of the 22 men who ran 26.2 miles; these urines were brownish to very dark burgundy red. Observations on 1 of these 4 athletes showed the occurrence of hemoglobinuria again after a 20 -mile run.

4. The occurrence of intravascular hemolysis appeared to be unrelated to the age, body build, or standing position of the runners, or to the number of years or state of their training.

5. Hemoglobinemia and hemoglobinuria disappeared in a few hours after the end of the run. It has been calculated that the amount of blood destroyed intravascularly is very small.

6. The plasma bilirubin was distinctly elevated after the marathon run. The significance of this hyperbilirubinemia is discussed.

7. Quantitative studies revealed normal erythrocyte fragility after the marathon runs.

8. Transient albuminuria was observed frequently after the 2.6 to 5.1 -mile runs and in every instance after the marathon run. Transient urinary excretion of formed elements occurred frequently after the shorter runs and in almost every instance after the marathon runs.

9. Hemoglobinemia sometimes accompanied by hemoglobinuria occurs in man with sufficient frequency after strenuous runs to be considered physiological under these conditions. This intravascular hemolysis after strenuous runs is comparable in its apparently benign nature to the albuminuria of exercise. The importance of differentiating this condition from pathological states leading to the passage of red urine is obvious.

We wish to acknowledge the cooperation of Dr. Andrew W. Contratto of the Department of Hygiene, Harvard University, Mr. Jaakko J. Mikkola, Track Coach, Harvard University, Mr. Thomas J. Kanaly of the Boston Athletic Association, and Mr. William T.
Wright, in arranging for the collection of the material of study, and the assistance in the field and laboratory of Drs. Howard A. Frank, Paul M. Zoll, and Norman Zamcheck.

\section{BIBLIOGRAPHY}

1. Gilligan, D. R., and Blumgart, H. L., March hemoglobinuria. Studies of the clinical characteristics, blood metabolism and mechanism; with observations on three new cases and review of the literature. Medicine, 1941, 20, 341.

2. Ham, T. H., Studies on destruction of red blood cells. I. Chronic hemolytic anemia with paroxysmal nocturnal hemoglobinuria: An investigation of the mechanism of hemolysis, with observations on five cases. Arch. Int. Med., 1939, 64, 1271.

3. Gilligan, D. R., Altschule, M. D., and Katersky, E. M., Studies of hemoglobinemia and hemoglobinuria produced in man by intravenous injection of hemoglobin solutions. J. Clin. Invest., 1941, 20, 177.

4. Bing, F. C., and Baker, R. W., Determination of hemoglobin in minute amounts of blood by Wu's method. J. Biol. Chem., 1931, 92, 589.

5. Bing, F. C., Purification of benzidine, and an improved reagent, for estimating hemoglobin in blood. J. Biol. Chem., 1932, 95, 387.

6. Malloy, H. T., and Evelyn, K. A., The determination of bilirubin with the photoelectric colorimeter. J. Biol. Chem., 1937, 119, 481.

7. Hunter, F. T, A photoelectric method for quantitative determination of erythrocyte fragility. J. Clin. Invest., 1940, 19, 691.

8. Dickinson, L., Haemoglobinuria from muscular exertion. Tr. Clin. Soc. London, 1894, 27, 230.

9. Attlee, W. H. W., Haemoglobinuria following exertion. Lancet, 1937, 1, 1400.

10. Finny, C. M., Functional hemoglobinuria. Brit. M. J., 1926, 2, 685.

11. Häntzschel, K., Ein Fall von echter Marschhämoglobinurie. Med. Klin., 1939, 35, 976.

12. Fisher, A. M., and Bernstein, A., March hemoglobinuria. A case report. Bull. Johns Hopkins Hosp., 1940, 67, 457.

13. Jundell, I., and Fries, K. A. E., Die Anstrengungsalbuminurie. Eine Studie über die Einwirkung maximaler Körperanstrengungen (des Sports und des Trainings) auf die Nieren. Nord. med. Arkiv., 1911, 44, Afd. II. N :r 2, 1.

14. Hastings, A. B., The physiology of fatigue. Physicochemical manifestations of fatigue in the blood. Public Health Bull., 117, 1921.

15. Ottenberg, R., and Fox, C. L., Jr., The rate of removal of hemoglobin from the circulation and its renal threshold in human beings. Am. J. Physiol., 1938, 123, 516.

16. Albu, A., and Caspari, W., Bericht über die Untersuchungen an den Dauergehern beim Distanzmarsch 
Dresden-Berlin am 18/19 Mai 1902. Deutsche med. Wchnschr., 1903, 29, 252.

17. Feigl, J., Chemische Blutuntersuchungen an der Teilnehmern eines Armee-Gepäckmarsches. I. Uber Umsatz und Ausscheidung von Blutfarbstoff. Hämoglobinämie, Hämatinämie und Hämoglobinurie. Biochem. Ztschr., 1916, 76, 88.

18. Foerster, A., Ueber Marschhämoglobinurie. München. med. Wchnschr., 1919, 66, 554.

19. Watson, E. M., and Fischer, L. C., Paroxysmal "march" hemoglobinuria. With a report of a case. Am. J. Clin. Path., 1935, 5, 151.

20. Hamburger, L. P., and Bernstein, A., Chronic hemolytic anemia with paroxysmal nocturnal hemoglobinuria. Am. J. M. Sc., 1936, 192, 301.

21. Witts, L. J., The paroxysmal haemoglobinurias. Lancet, 1936, 2, 115.

22. Porges, O., and Strisower, R., Offizielles Protokoll der k.k. Gesellschaft Aerzte in Wien. Ein Fall von Marschhämoglobinurie. Wien. klin. Wchnschr., 1913, 26, 193.

23. Porges, O., and Strisower, R., Über Marschhämoglobinurie. Deutsches Arch. f. klin. Med., 1914, 117, 13.

24. Schellong, F., Untersuchungen über Marschhämoglobinurie; ihre Beziehung zur Kältehämoglobinurie und orthostatischen Albuminurie. Ztschr. f. d. ges. exper. Med., 1923, 34, 82.

25. Broun, G. O., Blood destruction during exercise. II. Demonstration of blood destruction in animals exercised after prolonged confinement. J. Exper. Med., 1923, 37, 113.

26. Broun, G. O., Blood destruction during exercise. III. Exercise as a bone marrow stimulus. J. Exper. Med., 1923, 37, 187.

27. Broun, G. O., Blood destruction during exercise. IV. The development of equilibrium between blood de- struction and regeneration after a period of training. J. Exper. Med., 1923, 37, 207.

28. McMaster, P. D., Broun, G. O., and Rous, P., Studies on the total bile. I. The effect of operation, exercise, hot weather, relief of obstruction, intercurrent disease and other normal and pathological influences. J. Exper. Med., 1923, 37, 395.

29. Chang, H. C., and Harrop, G. A., Jr., The determination of the circulating blood volume with carbon monoxide. J. Clin. Invest., 1928, 5, 393.

30. Keys, A., and Taylor, H., The behavior of the plasma colloids in recovery from brief severe work and the question as to the permeability of the capillaries to proteins. J. Biol. Chem., 1935, 109, 55.

31. Kaltreider, N. L., and Meneely, G. R., The effect of exercise on the volume of the blood. J. Clin. Invest., 1940, 19, 627.

32. Hurtado, A., Studies at high altitude. Blood observations on the Indian natives of the Peruvian Andes. Am. J. Physiol., 1932, 100, 487.

33. Barron, E. S. G., Bilirubinemia. Medicine, 1931, 10, 77.

34. Leube, W., Ueber die Aussheidung von Eiweiss im Harn des gesunden Menschen. Arch. f. path. Anat. u. Physiol. u. f. klin. Med., 1878, 72, 145.

35. McFarlane, A., The presence of albumin and casts in the urine of football players. M. Rec., 1894, 46, 769.

36. Frenkel-Tissot, H. C., Zur Frage der sportlichen Albuminurie, besonders bei Skifahrern. Ztschr. f. klin. Med., 1921, 90, 54.

37. Edwards, H. T., Richards, T. K., and Dill, D. B., Blood sugar, urine sugar and urine protein in exercise. Am. J. Physiol., 1931, 98, 352.

38. Covian, F. G., and Rehberg, P. B., Uber die Nierenfunktion während schwerer Muskelarbeit. Skandinav. Arch. f. Physiol., 1936, 75, 21. 